\title{
Aneurysm rupture after choledochoduodenostomy with lumen-apposing metal stent: endoscopic ultrasound-guided stenting of the bile duct in an endoscopically blind situation due to massive bleeding
}

Choledochoduodenostomy is now an alternative treatment when endoscopic retrograde cholangiopancreatography fails to drain the bile duct [1-3]. However, the apposition stent can cause artery erosion leading to severe bleeding $[4,5]$.

We report the case of a 56-year-old man with pancreatic cancer. Owing to dilation of the biliary tract, a choledochoduodenostomy was performed using a lumenapposing metal stent (LAMS - Hot Axios; Boston Scientific, Marlborough, Massachusetts, USA). Although the procedure was effective during the early stages, 10 months later two obstructions occurred that required first placement of a double-pigtail stent and then mechanical deobstruction.

A few minutes before the patient came into the operating room for de-obstruction, he presented hematemesis and signs of hemorrhagic collapse. After a failed attempt to find the LAMS with a colonoscope because of massive bleeding, we decided to use endoscopic ultrasound (EUS) to detect the LAMS within the large amount of blood. Under EUS guidance ( $\vee$ Fig. 1, Video 1), the center of the LAMS was punctured in order to introduce a guidewire (endoscopically and blindly), and two covered metallic stents were deployed in the biliary tract. Blood pressure was stabilized at the end of the procedure.

Immediately after the procedure, computed tomography scan showed a large hepatic artery aneurysm with remaining blush. Radiologists successfully placed a covered metallic stent ( $\triangleright$ Fig. 2 ) and the aneurysm was excluded. Unfortunately, a few days later, the patient died in the intensive care unit, probably due to massive tumor bleeding.
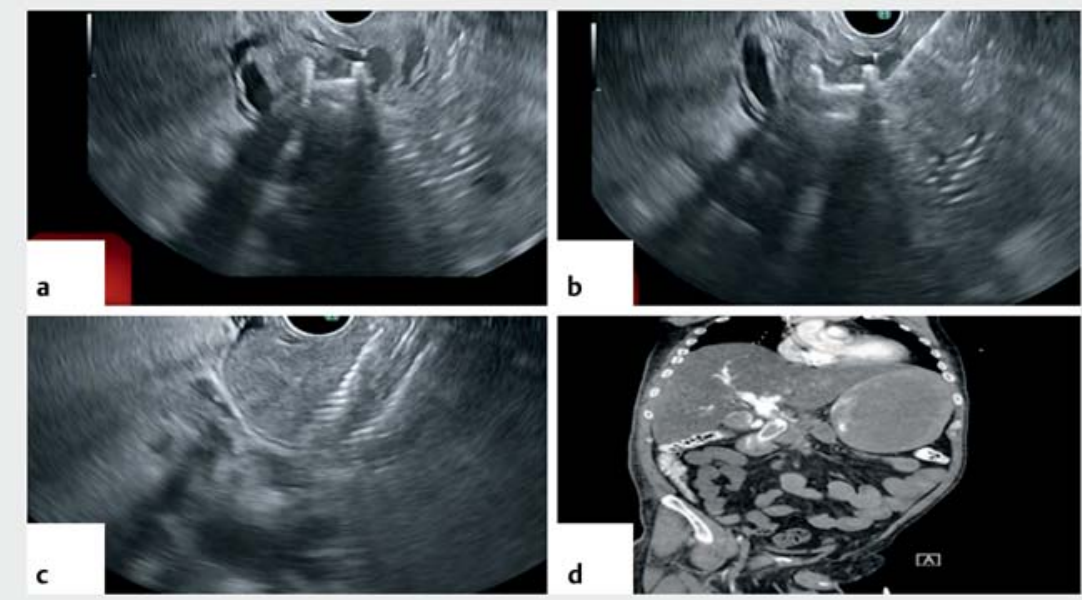

Fig. 1 Massive hemorrhage prevented the lumen-apposing metal stent (LAMS) from being located. a The LAMS was detected using endoscopic ultrasound (EUS). $\mathbf{b}$ The center of the LAMS was punctured under EUS guidance. $\mathbf{A}$ A covered metallic stent was deployed in the biliary tract. $\mathbf{d}$ Abdominopelvic computed tomography scan performed the same day showed the covered metallic stent inside the LAMS and intragastric bleeding from the hepatic artery.

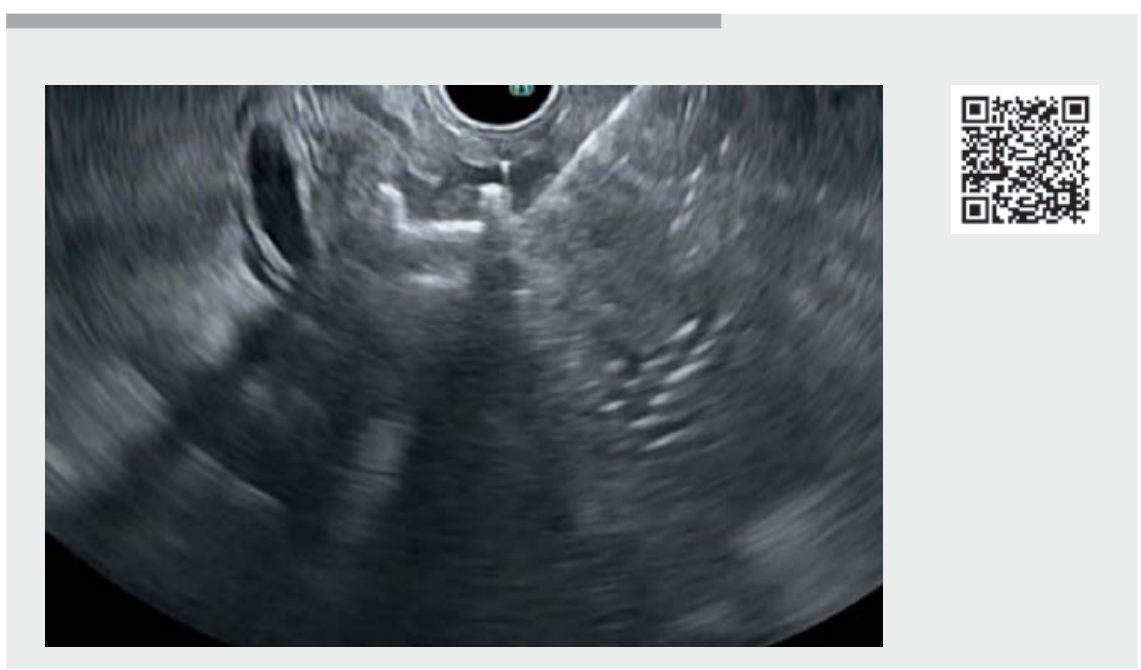

$\nabla$ Video 1 Aneurysm rupture after choledochoduodenostomy with a lumen-apposing metal stent. Stenting of the bile duct under endoscopic ultrasound guidance in an endoscopically blind situation due to the massive bleeding. 

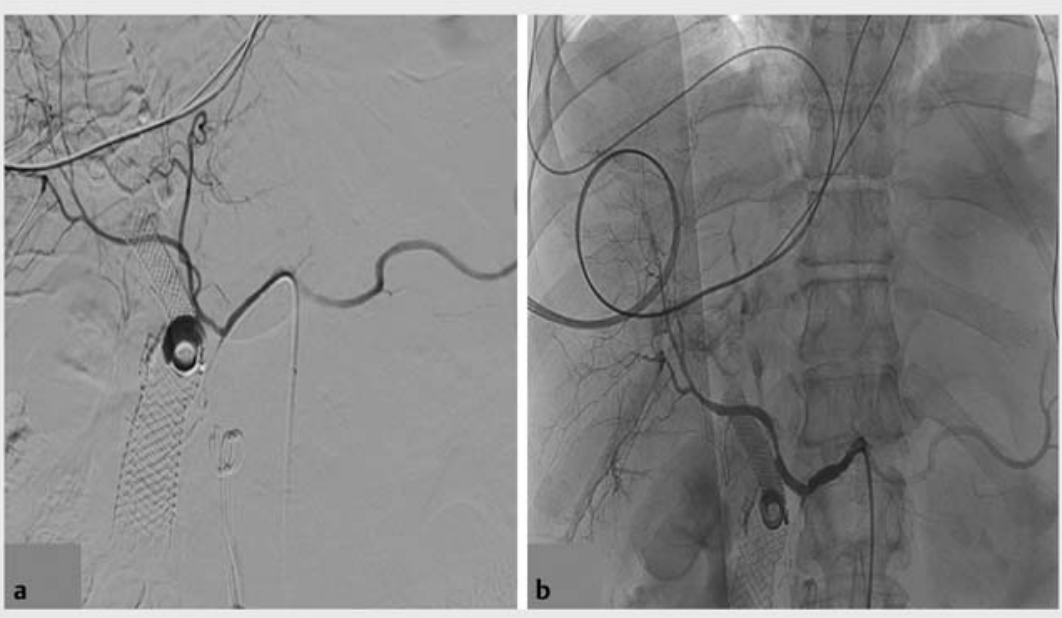

- Fig. 2 Angiography performed by interventional radiology. a Extravasation of contrast indicated bleeding from a hepatic artery aneurysm. $\mathbf{b}$ Successful embolization of the bleeding aneurysm was achieved, next to the covered metallic stent.

This case underlines the risk of choledochoduodenostomy when placed for several month and the important help that ultrasound-guided techniques can offer to detect the bile duct and bleeding source in cases of massive bleeding that precludes endoscopic guidance.

\section{Endoscopy_UCTN_Code_CPL_1AL_2AD}

\section{Competing interests}

The authors declare that they have no conflict of interest.

The authors

Jane-Rose Paccard ${ }^{1}$, Thomas Lambin ${ }^{1}$, Jérôme Rivory ${ }^{1}$, Florian Rostain ${ }^{1}$, Arnaud Thivolet ${ }^{2}$, Pierre Lafeuille ${ }^{1}$, Mathieu Pioche ${ }^{1}$

1 Department of Endoscopy and Hepatogastroenterology, Pavillon L, Edouard Herriot Hospital, Lyon, France

2 Department of Radiology, Pavillon B, Edouard Herriot Hospital, Lyon, France
Corresponding author

Mathieu Pioche, MD, PhD

Endoscopy Unit - Digestive Disease Department, Pavillon L - Edouard Herriot Hospital, 69437 Lyon Cédex, France mathieu.pioche@chu-lyon.fr

\section{References}

[1] Jacques J, Privat J, Pinard F et al. Endoscopic ultrasound-guided choledochoduodenostomy with electrocautery-enhanced lumenapposing stents: a retrospective analysis. Endoscopy 2019; 51: 540-547

[2] Jacques J, Privat J, Pinard $F$ et al. EUS-guided choledochoduodenostomy by use of electrocautery-enhanced lumen-apposing metal stents: a French multicenter study after implementation of the technique (with video). Gastrointest Endosc 2020; 92: 134-141

[3] Kunda R, Pérez-Miranda M, Will U et al. EUS-guided choledochoduodenostomy for malignant distal biliary obstruction using a lumen-apposing fully covered metal stent after failed ERCP. Surg Endosc 2016; 30: 5002-5008
[4] Gajjar B, Aasen T, Goenka P et al. Massive upper gastrointestinal bleeding following LAMS (lumen-apposing metal stent) placement. J Investig Med High Impact Case Rep 2020; 8: 2324709620965800

[5] Brimhall B, Han S, Tatman PD et al. Increased incidence of pseudoaneurysm bleeding with lumen-apposing metal stents compared to double-pigtail plastic stents in patients with peripancreatic fluid collections. Clin Gastroenterol Hepatol 2018; 16: 1521-1528

\section{Bibliography}

Endoscopy 2022; 54: E322-E323

DOI 10.1055/a-1529-5164

ISSN 0013-726X

published online 9.7.2021

(C) 2021. Thieme. All rights reserved.

Georg Thieme Verlag KG, Rüdigerstraße 14,

70469 Stuttgart, Germany

\section{ENDOSCOPY E-VIDEOS \\ https:|/eref.thieme.de/e-videos}

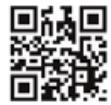

Endoscopy E-Videos is an open access online section, reporting on interesting cases and new techniques in gastroenterological endoscopy. All papers include a high quality video and all contributions are freely accessible online. Processing charges apply (currently EUR 375), discounts and wavers acc. to HINARI are available.

This section has its own submission website at https://mc.manuscriptcentral.com/e-videos 